\title{
Comparison of Certain Physical and Performance Parameters of Young Football Players Based on Positions
}

\author{
Ahmet Atl1 (Corresponding Author) \\ School of Physical Education and Sport, Iğdır University, Turkey \\ Tel: 90-476-223-0010Ｅ-mail: atliahmett@gmail.com
}

Received: April 12, 2021 Accepted: May 15, $2021 \quad$ Published: May 31, 2021

doi:10.5296/jei.v7i1.18527 URL: https://doi.org/10.5296/jei.v7i1.18527

\begin{abstract}
This study, which included 50 young amateur male footballers aged between 16 and 18, aims to compare certain physical and performance parameters of young football players based on positions. Based on their positions, the footballers were divided into two groups as "central" and "wing" positioned players. The body composition, anaerobic power, speed and flexibility values have been determined using field tests. The data were analyzed using SPSS 22 statistics program. Shapiro-Wilk test was used to determine the normality distribution of the data. The independent t-test was used because of the normal distribution of the data. Confidence interval for statistical processes was considered to be $p<0.05$. The average values and comparison results obtained from the physical parameters of the central and wing players have showed that there is a statistically significant difference between central and wing players in terms of height $(\mathrm{cm})$, body weight $(\mathrm{kg})$, fat mass $(\mathrm{kg})$ and lean mass $(\mathrm{kg})$ parameters $(\mathrm{p}<0.05)$, whereas there is no statistically significant difference in age (years) and fat rate $(\%)$ parameters $(\mathrm{p}>0.05)$. The average values and comparison results obtained from the physical parameters of the central and wing players have showed that there is a statistically significant difference between central and wing players in terms of vertical jump $(\mathrm{cm}), 30-\mathrm{m}$ sprint $(\mathrm{s})$ and anaerobic power $(\mathrm{kgm} / \mathrm{sec})$ parameters $(\mathrm{p}<0.05)$, whereas there is no statistically significant difference in $10-\mathrm{m}$ sprint $(\mathrm{s})$ and flexibility $(\mathrm{cm})$ parameters $(\mathrm{p}>$ 0.05). The results of this study showed that, in terms of physical parameters, the height, body weight, fat mass and lean mass values of the central players were statistically higher than the wing players. In terms of performance parameters, the vertical jump and $30-\mathrm{m}$ sprint performance of the wing players were found to be statistically better than the central players, while the anaerobic power values of the central players were found to be statistically higher than the wing players.
\end{abstract}


Keywords: Central position, Flexibility, Speed, Vertical jump, Wing position

\section{Introduction}

Football is defined as a sports branch characterized by short sprints, sudden acceleration and deceleration, turns, jumps and struggles (Dellal et al., 2010). Movements at a certain time during a competitive football match have a significant effect on the success. The studies reported that the players run between 10.50 and $11.77 \mathrm{~km}$ per game and $9.2 \%$ of the physical loads are considered to be high density. The study by Di Salvo et al. (2007) reported that there is a decrease in the total distance covered over time in high-intensity games. Moreover, the study by Bradley et al. (2009) indicated that the total distance run at high intensity in the last 15 -min of the match was $20 \%$ less than the distance covered in the first 15 -min period. The studies reported that these physical parameters are analyzed based on different position roles (Barros et al., 2007; Bloomfield et al., 2007).

Moreover, a midfielder runs a significantly longer distance than a defender or a striker in a professional match. A defender dribbles at a shorter distance than players in other positions, whereas they do much more sprinting than a striker, a defender, or a midfielder (Rampinini et al., 2007). In addition to the different physiological parameters between the positions, professional football players have position differences in terms of anthropometric aspects such as total body mass, height and body mass index (Wong et al., 2009). This suggests that certain physiological requirements and anthropometric prerequisites exist for different positions, and therefore young players with physiological performance and anthropometric superiority remain ahead of the game (Gil et al., 2007; Gravina et al., 2008).

However, the requirements during the match vary in youth team categories, and therefore the physical and physiological profiles of the players differ from the adult players. Independent factors such as age, biological maturity, training age, morphology and anthropometry have an effect on the physical and physiological profile of the players (Da Silva et al., 2008; Wong et al., 2008). The average running distance for the U18 and U12 categories is about 9 and 6.2 $\mathrm{km}$, respectively, and the game intensity is lower for the young footballers. Heart rate responses and blood lactate concentrations are lower in young football players compared to adult players. Therefore, the selection of players for a certain position based on their physiological performance is not suitable for young age groups (Capranica et al., 2001; Stolen et al., 2005). Accordingly, there is a limited number of studies investigating positional differences in physiological performance among young football players, however, the results vary (Gil et al., 2007). The study by Malina et al. (2000) including 14-year-old elite young footballers with 4.5 years of training experience, reported that there is no difference between defenders, midfielders and strikers in terms of vertical jump values, 30-m sprint time and aerobic endurance values.

The study by Gil et al. (2000) reported that goalkeepers have significantly lower aerobic capacity compared to defenders, midfielders, and strikers. Moreover, strikers have the best performance in 30-m sprints and vertical jumps compared to goalkeepers, defenders and midfielders. The study by D. P. Wong and S. H. S. Wong (2009) examined 70 male football players in the U14 category with five years of training experience and reported that there are 
significant anthropometric position differences among young football players, but there is no significant positional difference in terms of physiological performances.

The study by Reilly et al. (2000) examined 31 young male footballers and reported that top-level elite players have lower body weight, more aerobic strength, and more tolerance to fatigue than mid-level players. The study by Da Silva et al. (2008) indicated that young Brazilian players present different physical and physiological profiles than European football players, especially their height is shorter and their aerobic capacity is lower. Based on the results of the studies, it has been considered that there is a requirement for further research to provide a complete physical and physiological profile based on different positions.

The primary purpose of this study is to help young football players create anthropometric and physiological profiles based on their positions. The secondary purpose is to determine the suitability of these profiles and features for competitive success. It is believed that these findings can facilitate talent identification, selection of young players, and training design.

\section{Method}

\subsection{Participants}

The study included 50 young amateur male footballers aged between 16 and 18. Based on their positions, the footballers were divided into two groups as "central" and "wing" positioned players. The group of central players (n: 25) included central back, central midfield and central forward players (average age, 17.46 \pm 2.71 years; average height, $178.54 \pm 5.69 \mathrm{~cm}$; average body weight, $72.47 \pm 9.83 \mathrm{~kg}$; average fat rate, $7.62 \pm 3.52 \%$; average fat mass, $6.45 \pm 3.36 \mathrm{~kg}$; and average lean mass, $66.02 \pm 7.41 \mathrm{~kg}$ ), and the group of wing players (n: 25) included wing back, wing midfield and wing forward players (average age, $17.63 \pm 2.36$ years; average height, $174.51 \pm 5.44 \mathrm{~cm}$; average body weight, $69.24 \pm 7.63 \mathrm{~kg}$; average fat rate, $7.18 \pm 2.84 \%$; average fat mass, $5.46 \pm 2.31 \mathrm{~kg}$; and average lean mass, $63.78 \pm 5.83 \mathrm{~kg})$.

\subsection{Research Design}

The body composition, anaerobic power, speed and flexibility values have been determined using field tests. The height measurements of the participants were made with a sensitivity of $0.1 \mathrm{~cm}$ using a stadiometer. Body weight $(\mathrm{kg})$, body fat ratio $(\%)$, body fat mass $(\mathrm{kg})$ and lean body masses $(\mathrm{kg})$ were determined by a body fat analyzer. The vertical jump measurements were made using a digital jump meter with a sensitivity of 0.1 centimeter $(\mathrm{cm})$, and their speed performance was determined by a $10-\mathrm{m}$ and $30-\mathrm{m}$ sprint tests. Sit and reach flexibility test was applied for the flexibility parameter. The calculation of anaerobic power was performed using the formula of $\mathrm{P}=\sqrt{4} .9 \times($ Weight $) \times \sqrt{ } \mathrm{Dn}$. "P" stands for power in kilogram-meters/second, and "Dn" stands for vertical jump distance in meters (Karakulak et al., 2019). 


\subsection{Data Collection Tools}

\subsubsection{Vertical Jump Test}

A digital jump meter with a $0.1 \mathrm{~cm}$ accuracy was used for vertical jump measurements in the performance tests. After the digital indicator of the jump meter was connected to the waist area and the rope was adjusted, the participant made the jump upward by stretching on his knees. After the jump, the participant tried to fall into the circular plastic area that was connected to the jump meter and placed on the ground. In the event of the participant taking a step forward or backward after landing, the jump was deemed invalid and repeated. The test was carried out twice, and the highest value was recorded in "cm".

\subsubsection{0 and 30-m Speed Test}

10 and 30-m sprint tests were applied to determine the speed performance of the participants. Photocells were placed at distances of 0 and 10-30-m. Before starting the test, the participants performed a warm-up protocol with 7-min of dynamic stretching and short sprinting after a 10-min warm-up run. The participants performed the test twice, after a 5-min rest interval. The best time of the two attempts was recorded. When the participant was ready, he started from $1 \mathrm{~m}$ behind the starting photocell; after reaching the end photocell at 10 and $30-\mathrm{m}$ distance with the highest speed that he could reach, the running time was recorded automatically. The test was carried out twice; and the highest value was recorded in "s".

\subsubsection{Sit and Reach Flexibility Test}

The flexibility test measurement of the athletes participating in the study was carried out with a sit and reach test box with a length of $35 \mathrm{~cm}$, a width of $45 \mathrm{~cm}$, and a height of $32 \mathrm{~cm}$. The participants sat on the ground and put their bare feet flat against the test box. The participants then stretched their hands in front of their body as far as they could by bending their torso forward, without bending their knees. The participants waited in this state for 1-2 $\mathrm{s}$ at the farthest point. The test was repeated twice, and the best value was determined in "cm".

\subsection{Analysis of Data}

The data were analyzed using SPSS 22 statistics program. Shapiro-Wilk test was used to determine the normality distribution of the data. The independent t-test was used due to the normal distribution of the data. Confidence interval for statistical processes was considered to be $\mathrm{p}<0.05$.

\section{Results}

The average values and comparison results obtained from the physical parameters of the central and wing players in Table 1 have showed that there is a statistically significant difference between central and wing players in terms of height $(\mathrm{cm})$, body weight $(\mathrm{kg})$, fat mass $(\mathrm{kg})$ and lean mass $(\mathrm{kg})$ parameters $(\mathrm{p}<0.05)$, whereas there is no statistically significant difference in age (years) and fat rate $(\%)$ parameters. 


\section{Macrothink}

Table 1. Average values and comparison results obtained from physical parameters of central and wing players

\begin{tabular}{|l|l|l|l|l|}
\hline Physical Parameters & Central Players & Wing Players & T & P \\
\hline Age (years) & $17.46 \pm 2.71$ & $17.63 \pm 2.36$ & 1.63 & 0.22 \\
\hline Height (cm) & $178.54 \pm 5.69$ & $174.51 \pm 5.44$ & 3.22 & $\mathbf{0 . 0 1 *}$ \\
\hline Body Weight (kg) & $72.47 \pm 9.83$ & $69.24 \pm 7.63$ & 3.60 & $\mathbf{0 . 0 2 *}$ \\
\hline Fat Rate (\%) & $7.62 \pm 3.52$ & $7.18 \pm 2.84$ & 1.58 & 0.39 \\
\hline Fat Mass (kg) & $6.45 \pm 3.36$ & $5.46 \pm 2.31$ & 2.17 & $\mathbf{0 . 0 3 *}$ \\
\hline Lean Mass (kg) & $66.02 \pm 7.41$ & $63.78 \pm 5.83$ & 3.39 & $\mathbf{0 . 0 1 *}$ \\
\hline
\end{tabular}

Note. ${ }^{*} \mathrm{p}<0.05$.

The average values and comparison results obtained from the performance parameters of the central and wing players in Table 2 have showed that there is a statistically significant difference between central and wing players in terms of vertical jump (cm), 30-m sprint (s) and anaerobic power $(\mathrm{kgm} / \mathrm{s})$ parameters $(\mathrm{p}<0.05)$, whereas there is no statistically significant difference in 10-m sprint $(\mathrm{s})$ and flexibility $(\mathrm{cm})$ parameters.

Table 2. Average values and comparison results obtained from performance parameters of central and wing players

\begin{tabular}{|l|l|l|l|l|}
\hline Performance Parameters & Central Players & Wing Players & T & P \\
\hline Vertical Jump (cm) & $54.62 \pm 6.21$ & $58.11 \pm 4.76$ & -2.28 & $\mathbf{0 . 0 1 *}$ \\
\hline 10-m Sprint (s) & $1.78 \pm 0.18$ & $1.75 \pm 0.11$ & 1.16 & 0.29 \\
\hline 30-m Sprint (s) & $4.33 \pm 0.19$ & $4.27 \pm 0.26$ & 2.62 & $\mathbf{0 . 0 2 *}$ \\
\hline Anaerobic Power (kgm/s) & $119.41 \pm 19.27$ & $113.25 \pm 13.47$ & 2.47 & $\mathbf{0 . 0 1 *}$ \\
\hline Flexibility (cm) & $28.36 \pm 6.52$ & $29.74 \pm 5.33$ & -1.13 & 0.42 \\
\hline
\end{tabular}

Note. ${ }^{*} \mathrm{p}<0.05$.

\section{Discussion}

This study, which included 50 young amateur male footballers aged between 16 and 18, aims to compare certain physical and performance parameters of young football players based on positions. According to the results of this study, physical parameters such as height, body weight, fat mass and lean mass of central players were determined to be higher than wing 
players. It was observed that the performance parameters of wing players such as vertical jump and 30-m speed were higher than the central players. In addition, the anaerobic power values of the central players were found to be higher than the wing players.

As one of the important results of the study, the height and body weight values of the central players were found to be higher than the wing players. When many studies conducted to evaluate the physical and performance parameters of football players who play in different positions are examined, it is possible to come across various studies that support the results of this study. The studies indicated in terms of physical characteristics that the average height of an average football player is $180 \mathrm{~cm}$ and the percentage of body fat is between $7 \%$ and $14 \%$ (Rico-Sanz, 1998). Accordingly, it was suggested that especially low-fat percentage gives a player an advantage in both running and jumping performances (Strudwick et al., 2002).

The study by Aslan and Koç (2015) examined 70 amateur footballers with an average age of $22.11 \pm 2.71$ years based on their positions and body weights, and stated that forward players have higher body weight than midfielders and defenders. The study by Akçınar (2009) reported that the average height of defensive football players and offensive football players is $181.92 \pm 5.12 \mathrm{~cm}$ and $178.75 \pm 5.91 \mathrm{~cm}$, respectively. Midfielders have characteristics of running so much due to their position, and defenders are tall since they have to fight and interfere with the air balls, which provides an advantage over the opposing team (Tourney \& Leroy, 2002). When the results of the studies are examined, the results of this study support previous findings.

Independent factors such as age, biological maturity, training age, morphology and anthropometry have an effect on the physical and physiological profile of the players (Da Silva et al., 2008; Wong et al., 2008). Features such as height and body weight in football provide advantages over different positions of the game. In football, it is expected feature for central back players to be taller. This enables central back players to defend better against air balls and corners in football. Central midfield players are also the players who are mostly in tandem struggle, so their height and body weight should be higher. In addition, central forward players are expected to have higher height and body weight in order to gain advantage in air balls and corners during attack. Moreover, central forward players can turn these features into an advantage, as they are constantly in a struggle with defenders. According to the results of the study, it is thought that the fact that the central players have better height and body weight values compared to the wing players is due to these reasons.

As one of the other important results of the study, the fat mass and lean mass values of the central players were found to be higher than the wing players. Based on the current results in terms of body mass index, it has been considered that anthropometric features contribute to success in certain high-level positions. For example, players who are taller and have higher body weight are more suitable for the central position, while players who are shorter and have lower body weight are more suitable for the wing position (Di Salvo et al., 2009). The study by Al-Hazza (2001) found the average body fat ratio of professional football players to be $12.3 \%$, whereas the study by Rico-Sanz (1998) found the average body fat ratio of La Liga players to be $10 \%$. In a study, including 20 football players who have played in the Turkish 
Football Federation Third League, the body fat ratio was $11.27 \pm 2.29 \%$. In another study including 33 professional footballers in the Second League, this rate was $10.81 \pm 0.27 \%$ (Kayatekin et al., 1993). In a study including 18 football players in the Second League, the body fat ratio varied between $9.66 \pm 1.10$ and $11.52 \pm 1.05 \%$ (Koç et al., 2000). The studies conducted with senior football players reported that the sprint duration of players with low body fat rate are positively low, in other words, there is an increase in their sprint performance (Turgay et al., 2003). When the results of the studies are examined, the results of this study support previous findings.

In addition to the different physiological parameters between the positions, professional football players have position differences in terms of anthropometric aspects such as total body mass, height and body mass index (Wong et al., 2009). Considering the structure of the game in football, it is seen that wing players are more active. In football, it is expected that the wing players will be faster than the central players due to the position. Wing players run more intensely than central players and also perform more sprint performance. In this direction, height and body weight ratios of wing players are important in performing these performances. Especially wing players are expected to have a shorter height and less body weight. For these reasons, as a result of the study, it is thought that the body composition values of wing players are lower than the central players.

According to another result of the research, 30-m speed performance values of wing players were found to be higher than central players. When studies with similar results are examined, in a study on speed performance, the average $30-\mathrm{m}$ sprint values based on the positions in the First League teams and the Second League teams were $4.07 \pm 0.12$ and $4.10 \pm 0.11 \mathrm{~s}$, respectively, and the average 30-m sprint values of 29 players in the Third League and 29 players in the Amateur League was $4.13 \pm 0.10$ and $4.16 \pm 0.12 \mathrm{~s}$, respectively (Eniseler et al., 2000). Another study found the average $30-\mathrm{m}$ sprint values of professional football players to be $4.28 \pm 0.16 \mathrm{~s}$ (Kizllet et al., 2004). The study by Turgay et al. (2003) including 77 football players in the Amateur League, reported that the average 30-m sprint value of goalkeepers, defenders, midfielders and strikers is $5.06 \mathrm{~s}, 4.59 \mathrm{~s}, 4.57 \mathrm{~s}$ and $4.59 \mathrm{~s}$, respectively. The study by Köse and Atlı (2020) reported the average 30-m sprint values $(4.04 \pm 0.08 \mathrm{~s})$ of the young football players. Moreover, the study by Cometti et al. (2001) revealed the 10-m sprint values $(1.80 \mathrm{~s})$ and $20-\mathrm{m}$ sprint values $(4.22 \mathrm{~s})$ of the football players. The results obtained in this study has indicated that the strikers have the best 10,20 and $30-\mathrm{m}$ sprint values $(10-\mathrm{m}$ : $1.67 \pm 0.09 ; 20$-m: $2.94 \pm 0.16 ; 30$-m: $4.15 \pm 0.20$ ). Another study by K1z1let et al. (2004) indicated that central defenders have a higher $30-\mathrm{m}$ speed performance compared to wing defenders. When the results of the studies are examined, the results of this study support previous findings.

Football is defined as a sports branch characterized by short sprints, sudden acceleration and deceleration, turns, jumps and struggles (Dellal et al., 2010). Movements at a certain time during a competitive football match have a significant effect on the success. Due to the position in football, wing players make more effort because they play in a wider area. Wing players perform a lot of repeated sprint performance in this wide area. Wing players practice both aspects of the game, especially during defense and offense. In addition, the physical 
characteristics of wing players are thought to provide an advantage in sprint performance compared to the central players. For these reasons, it can be said that the speed values of wing players are better than central players in the study.

According to another result of the study, vertical jump values of wing players were found better than central players, while central players achieved better results in anaerobic power performance than wing players. In previous studies, Reilly et al. (2000) stated the vertical jump average as $58.00 \pm 1.12 \mathrm{~cm}$ in their study with English league football players. Ek et al. (2007) determined the average of vertical jump test as $53.65 \pm 5.34 \mathrm{~cm}$ in the study conducted with 26 football players. Malina et al. (2000) reported that goalkeepers achieved the best vertical jump values according to their positions, while wing midfield players achieved the lowest vertical jump values. Stolen et al. (2005) reported that goalkeepers have the highest jump height compared to strikers and defenders, while midfielders have the lowest jump height. When the results of the studies are examined, the results of this study support previous findings.

Bangsbo (1994) emphasized that for successful competitiveness, the development of speed, agility, strength with combination of aerobic and anaerobic (even maximal) abilities are important for successful, competitive football careers. In football, especially in amateur leagues, physical struggle takes place more than technical and tactical features. Players perform constant strength and power during the match. Especially physical properties and lower extremity strength are more important. This allows the players to perform better jump performance. For these reasons, it can be thought that central players have better vertical jump values than wing players in the study. Moreover, the calculation of anaerobic power was performed using the formula of $\mathrm{P}=\sqrt{4} .9 \times($ Weight $) \times \sqrt{ } \mathrm{Dn}$. "P" stands for power in kilogram-meters/second, and "Dn" stands for vertical jump distance in meters. According to this formula used in the calculation of anaerobic power, the height of the jump distance is very important. Height is quite an advantage for a good jumping distance. In this respect, it is thought that the anaerobic power values of the central players are higher than the wing players due to the greater height of the central players in the study.

\section{Conclusion}

The results of this study showed that, in terms of physical parameters, the height, body weight, fat mass and lean mass values of the central players were statistically higher than the wing players. In terms of performance parameters, the vertical jump and $30-\mathrm{m}$ sprint performance of the wing players were found to be statistically better than the central players, while the anaerobic power values of the central players were found to be statistically higher than the wing players. According to these results, physical and performance parameters should be taken into consideration while choosing the appropriate position especially for young football players. It is very important to evaluate these physical and performance parameters in the selection of central and wing players in football.

\section{References}

Akçınar, F. (2009). Evaluation of physical fitness and somatotype features of professional 
football team players (Malatyaspor Example). Elazığ: Firat University, Institute of Health Sciences.

Al-Hazza, H. M. (2001). Aerobic and anaerobic power characteristic of Saudi elite soccer players. Journal of Sports Medicine and Physical Fitness, 41, 54-61.

Aslan, C. S., \& Koç, H. (2015). Comparison of selected physical, physiological and motoric features of amateur football players according to their positions. CBU Journal of Physical Education and Sport Sciences, 10(1), 56-65.

Bangsbo, J. (1994). Fitness training in football-A scientific approach. Denmark: HO+ Storm: Bagsværd.

Barros, R., Misutal, M., Menezes, R., Figueroa, P. J., Moura, F. A., Cunha, S. A., Anido, R., $\&$ Leite, N. (2007). Analysis of the distances covered by first division Brazilian soccer players obtained with an automatic tracking method. J Sports Sci Med, 6, 233-242.

Bloomfield, J., Polman, R., \& O’Donoghue, P. (2007). Physical demands of different positions in FA Premier League soccer. J Sports Sci Med, 6, 63-70.

Bradley, P. S., Sheldon, W., Wooster, B., Olsen, P., Boanas, P., \& Krustrup, P. (2009). High-intensity running in English FA Premier League soccer matches. J Sports Sci, 27, 159-168. https://doi.org/10.1080/02640410802512775

Capranica, L., Tessitore, A., Guidetti, L., \& Figura, F. (2001). Heart rate and match analysis in pre-pubescent soccer players. J Sports Sci, 19, 379-384. https://doi.org/10.1080/ 026404101300149339

Cometti, G., Maffiuletti, N. A., \& Pousson, M. (2001). Isokinetic strenght and anaerobic power of elite, subelite and amateur French soccer player. International Journal Sports Medicine, 22, 45-51. https://doi.org/10.1055/s-2001-11331

Da Silva, C. D., Bloomfield, J., \& Martins, J. C. B. (2008). A review of stature, body mass and maximal oxygen uptake profiles of U17, U20 and first division players in Brazilian soccer. J Sports Sci Med, 7, 309-319.

Dellal, A., Chamari, C., Wong, D. P., Ahmaidi, S., Keller, D., Barros, M. L. R., Bisciotti, G. N., \& Carling, C. (2010). Comparison of physical and technical performance in European professional soccer match-play: The FA Premier League and La LIGA. Eur J Sport Sci, 11, 51-59. https://doi.org/10.1080/17461391.2010.481334

Di Salvo, V., Baron, R., Tschan, H., Calderon Montero, F. J., Bachl, N., \& Pigozzi, F. (2007). Performance characteristics according to playing position in elite soccer. Int J Sports Med, 28, 222-227. https://doi.org/10.1055/s-2006-924294

Di Salvo, V., Gregson, W., Atkinson, G., Tordoff, P., \& Drust, B. (2009). Analysis of high intensity activity in Premier League soccer. Int J Sports Med, 30, 205-212. https://doi.org/ $10.1055 / \mathrm{s}-0028-1105950$

Ek, O. R., Temoçin, S., \& Atatekin, T. (2007). Investigation of the effects of some tests 
applied in football training. Journal of Adnan Menderes University Faculty of Medicine, 8(1), 19-22.

Eniseler, N., Çolakoğlu, M., \& Altun, M. (2000). Relationship with H/Q, knee bilateral, and hamstring Ecc/Con force ratios and 10-30-m sprint performance in 1st League football players (pp. 17-20). II. Football and Science Congress; Program and Abstracts Booklet.

Gil, S. M., Gil, J., Ruiz, F., Irazusta, A., \& Irazusta, J. (2007). Physiological and anthropometric characteristics of young soccer players according to their playing position: Relevance for the selection process. J Strength Cond Res, 21, 438-445. https://doi.org/ $10.1519 / 00124278-200705000-00026$

Gravina, L., Gil, S. M., Ruiz, F., Zubero, J., Gil, J., \& Irazusta, J. (2008). Anthropometric and physiological differences between first team and reserve soccer players aged 10-14 years at the beginning and end of the season. J Strength Cond Res, 22, 1308-1314. https://doi.org/ 10.1519/JSC.0b013e31816a5c8e

Karakulak, İ., Eyuboğlu, E., \& Aslan, C. S. (2019). Comparison of physical and motoric properties of central and wing players in football. Spormetre Journal of Physical Education and Sports Sciences, 17(2), 126-131. https://doi.org/10.33689/spormetre.542468

Kayatekin, et al. (1993). Season of thirty-three football players playing in professional 2nd league football teams pre-physiological profiles. Journal of Sports Medicine, 28, 117-123.

Kızılet, A., Erdem, K., Karagözoğlu, C., Topsakal, N., \& Çalışkan, E. (2004). Evaluation of some physical and motor features of football players in terms of positions. Gazi Journal of Physical Education and Sport Sciences, 3, 67-78.

Koç, H., Gökdemir, K., \& Kılınç, F. (2000). The Effect of training between the season on some physical and physiological parameters of Kütahyaspor players. I. Gazi Physical Education and Sports Sciences Congress, Ankara.

Köse, B., \& Atl1, A. (2020). Investigation of the effect of high intensity interval training on agility speed and aerobic performance in young soccer players. Turkish Journal of Sports Sciences, 4(1), 61-68. https://doi.org/10.32706/tusbid.730085

Malina, R. M., Pena Reyes, M. E., Eisenmann, J. C., Horta, L., Rodrigues, J., \& Miller, R. (2000). Height, mass and skeletal maturity of elite Portuguese soccer players aged 11-16 years. J Sports Sci, 18, 685-693. https://doi.org/10.1080/02640410050120069

Rampinini, E., Coutts, A. J., Castagna, C., Sassi, R., \& Impellizzeri, F. M. (2007). Variation in top level soccer match performance. Int J Sport Med, 28, 1018-1024. https://doi.org/ $10.1055 / \mathrm{s}-2007-965158$

Reilly, T., Bangsbo, J., \& Franks, A. (2000). Anthropometric and physiological predispositions for elite soccer. Journal of Sports Sciences, 18(9), 669-683. https://doi.org/ $10.1080 / 02640410050120050$

Reilly, T., Williams, A. M., Nevill, A., \& Franks, A. A. (2000). Multidisciplinary approach to 
talent identification in soccer. $J$ Sports Sci, 18, 695-702. https://doi.org/10.1080/ 02640410050120078

Rico-Sanz, J. (1998). Body composition and nutritional assessment in soccer. International Journal of Sport Nutrition, 8, 113-123. https://doi.org/10.1123/ijsn.8.2.113

Stolen, T., Chamari, K., Castagna, C., \& Wisloff, U. (2005). Physiology of soccer: An update. Sports Med, 35, 501-536. https://doi.org/10.2165/00007256-200535060-00004

Strudwick, A., Reilly, T., \& Doran, D. (2002). Anthropometric and fitness profiles of elite players in two football codes. Journal of Sports Medicine and Physical Fitness, 42, 239-242. https://doi.org/10.4324/9780203474235-11

Tourney-Chollet, C., \& Leroy, D. (2002). Conventional vs. dynamic hamstring quadriceps strength rations: a comparison between players and sedentary subjects. Isokinetic Exer Sci, 10, 183-192. https://doi.org/10.3233/IES-2002-0102

Turgay, F., Çecen, A., Karamızrak, O., \& Acarbay, Ş. (2003). Physical and physiological profile of Turkish professional football players (p. 405). 9. National Sports Medicine Congress Book.

Wong, D. P., \& Wong, S. H. S. (2009). Physiological profile of Asian elite youth soccer players. J Strength Cond Res, 23, 1383-1390. https://doi.org/10.1519/JSC.0b013e3181a4f074

Wong, P. L., Chamari, K., Dellal, A., \& Wisløff, U. (2009). Relationship between anthropometric and physiological characteristics in youth soccer players. J Strength Cond Res, 23, 1204-1210. https://doi.org/10.1519/JSC.0b013e31819f1e52

Wong, P., Mujika, I., Castagna, C., Chamari, K., Lau, P. W. C., \& Wisloff, U. (2008). Characteristics of World Cup soccer players. Soccer J, 57-62.

\section{Copyright Disclaimer}

Copyright for this article is retained by the author(s), with first publication rights granted to the journal.

This is an open-access article distributed under the terms and conditions of the Creative Commons Attribution license (http://creativecommons.org/licenses/by/3.0/). 